\title{
Nutrient Flows in Perennial Crop-Based Farming Systems in the Humid Forests of Cameroon
}

\author{
Eugene Ejolle Ehabe ${ }^{1 *}$, Nomo Lucien Bidzanga ${ }^{2}$, Charles-Magloire Mba ${ }^{1}$, Jetro Nkengafac Njukeng ${ }^{1}$, \\ Inacio de Barros ${ }^{3}$, Frank Enjalric ${ }^{4}$ \\ ${ }^{1}$ Institute of Agricultural Research for Development (IRAD), Ekona Regional Research Centre, PMB 25 Buea, Cameroon; ${ }^{2}$ Institute \\ of Agricultural Research for Development (IRAD), Nkolbisson, Yaounde, Cameroon; ${ }^{3}$ INRA Antilles-Guyana, URAPC, Guadeloupe \\ (FWI); ${ }^{4}$ Unité Mixte de Recherche Système, CIRAD Cultures Pérennes, Montpellier, France . \\ Email: "e_ehabe@yahoo.com
}

Received August $4^{\text {th }}, 2010$; revised August $24^{\text {th }}, 2010$; accepted September $11^{\text {th }}, 2010$

\begin{abstract}
A study was conducted in some perennial crop-based farms in the humid forests of South West Cameroon, to better understand their soil fertility patterns and management and identify factors that contribute most to nutrient depletion trends in such multi-storey farmholdings. The main perennial crops were the para rubber tree (Hevea brasiliensis), cocoa (Theobroma cacao) and oil palm (Eleais guineensis) whose ages ranged from immature to very old (senescence). Data were collected over a two-year period (2007 and 2008) and modelled using the farm NUTrient MONitoring (NUTMON) tool. Results showed that the farming systems played key roles in the overall exploitation strategies. Plantain and cassava (annual crops) and cocoa (perennial) were the most associated crops, accounting for more than half of intercropped frequencies. Whereas nutrient flows within and between farm units were confirmed, the net loss in soil $N, P$ and $K$ nutrient balances differed with the main perennial crop - being highest for the oil palm and lowest for the rubber tree. The average nutrient balance of each farm was markedly negative for $N$ but positive for $P$ and $K$. Partial nutrient balance (ignoring biophysical flows like $N$-fixation, leaching and erosion) was positive for the three nutrients indicating therefore that the biophysical flows accounted more for $N$ depletion. Nitrogen loss was mainly due to, leaching ( 70\%), volatilization ( $20 \%)$, and exported crops and their residues.
\end{abstract}

Keywords: Soil Fertility, Nutrient Monitoring, Depletion, Nutmon

\section{Introduction}

Crop production practices within peasant farm holdings in sub-Saharan Africa often progress at the expense of sustainable land use as farmers are primarily concerned about crop and animal production, for the forthcoming season. Hence, long-term processes that adversely affect sustainability, such as decrease and eventual depletion of soil nutrient stocks, are less visible and receive a lower priority. Most often, these soils are progressively being mined of their nutrients [1] whereas there is need to secure present productivity and ensure the sustainability of these farming systems. These farmers have to manage the fertility of their soils by manipulating the flows of nutrients into, out of and within the farm. Indeed, decisions concerning soil productivity are determined by household objectives (food security, profit or cash maximization, risk aversion, long term security of livelihood, etc.), available resources (labour, cash, implements, natural resources, etc.) and the socio-economic environment.
Soil fertility in sub-Saharan Africa is today regarded as a major survival issue, especially in peasant perennial crop-based systems in the humid forests of Cameroon. This project was initially undertaken to ensure a better understanding and improvement of soil fertility in these cropping systems, to determine the possible role of integrated nutrient management in reversing present trends of nutrient depletion at each farm-level, and to integrate quantitative and qualitative assessment approaches in managing soil fertility.

The complexity of peasant farms does not always allow for quantification of all flows and stocks. Nutrient monitoring (NUTMON) is a multi-scale modelling approach that was conceived to assess stocks and flows of certain nutrients in a well defined geographical unit following a strict monitoring of all farm inputs (mineral fertilizers, manures, atmospheric deposition and sedimentation) and outputs (harvested crop produces, residues, leaching, denitrification, erosion losses). The NUTMON- 
Toolbox was developed with three modules to quantify nutrient flows, nutrient stocks and economic performance indicators for farms. It provides guidelines for data gathering in the field, data entry, calculation of flows and balances and data interpretation. Application of the tools from the toolbox results in a thorough analysis providing insight into nutrient flows between the various activities within the farm as well as between the farm and its surroundings [2].

The specific objectives of this study were therefore to evaluate variations of soil nutrient stocks at farm level, measure and estimate the major nutrient flows at farm level as a means to describe current farm nutrient management, to identify the key factors influencing land management in perennial crop-based farms in the humid forests of South West Cameroon in a bid to discover some of the underlying causes of soil fertility depletion. This was particularly supposed to be done using the Nutrient Monitoring Programme (NUTMON) or software, a tool that was developed to assess nutrient balances (stocks and flows of some macro-nutrients - N, P and K), biomass flow and economic performance at farm level [2].

NUTMON has been suggested as a decision-support model to monitor the effects of changing land use and suggest interventions that improve the nutrient balance [4]. As input and output determinants cannot all be quantified equally well, the model recognizes primary data, estimates and assumptions. The NUTMON determinants are mostly scale-neutral and can therefore be used to monitor nutrient balances at farm, regional, national and supranational levels.

NUTMON is fed by a number of basic data, and by nutrient input and output data [2]. Basic data include the surface area of the arable land, and the spatial patterns of land use systems (LUS). Nutrient input and output data are reflections of different processes, each of which has a certain value (the nutrient balance) which is specific for a given LUS at a given time. A second monitoring exercise at a later stage may yield different results, which may be due to changes in the LUS, or changes in the individual nutrient input and output values. As the changes have either aggravated or ameliorated the nutrient balance, NUTMON can support decision-making in the interest of sustainable forms of agriculture [3,5].

\section{Methodology}

\subsection{The Study Area}

Field observations were carried out on 19 typical perennial crop-based agroforestry farms, distributed around $\mathrm{Ku}-$ mba and extending to the Bombe-Malende zones (4 ${ }^{\circ} 25^{\prime}-$ $4^{\circ} 80^{\prime} \mathrm{N}$ and $\left.9^{\circ} 25^{\prime}-9^{\circ} 35^{\prime} \mathrm{E}\right)$ in the South West Region of Cameroon (Figure 1). This region falls within the rain- forest area (mean rainfall of 2,852 mm/yr), with a marked rainy season (March to October), and high mean annual temperatures $\left(\sim 23^{\circ} \mathrm{C}\right)$ evenly distributed throughout the year [6], Soils are ferrallitic with patches of fertile volcanic areas, and altitudes varying from 25 to $400 \mathrm{~m}$ toward the North. The agro-forestry exploitations existing in the area are typically characterized as home gardens [7], that is, permanently occupied (no fallow) small areas, usually adjacent to the farmers' houses, integrating main perennials (oil palm, rubber trees and cocoa), food crops (yams, cassava, maize, banana, plantain, cocoyam, etc.), and native trees (as well as ornamentals and medicinal plants not considered in the surveys).

The farm holdings had been judged homogeneous in terms of their farm and non-farm economic activities as well as the presence of some perennials as main crop in association with other crops. These farm types ranged from small-scale holdings with mostly food crops, industrial plantations for export crops and intercropped farms having various combinations of perennial and food crops [8,9]. The main crops, their development stages and basic characteristics of the terrain of the studied farms are presented in Table 1. The parent material of all the soils was of a volcanic/basement complex [1,10].

Prior to the survey, each farm was characterised for its location, altitude, rainfall and surface area, relief, soil morphology (depth, texture or clay content, colour, parent material) and composition (moisture status, rooting status, etc.).

\subsection{Soil Analyses}

For each plot, three to five representative samples were collected, following the procedure described latter on, and bulked. A soil observation was made at 100-m intervals using a soil auger to examine the soil down to a depth of $50 \mathrm{~cm}$ or more, when feasible. During such observations, several soil/land characteristics were noted, notably the slope, horizon differentiation, soil depth, texture, colour, coarse fragments, drainage conditions, etc. These were later on sorted into groups of similar soils and terrain. Similar soils were bulked, labelled and packaged for eventual laboratory analysis.

In the laboratory, the soils were dried under ambient conditions for about 2 weeks, crushed and sieved through a 2-mm mesh. The throughs were subjected to several standard soil analytical procedures, notably for their:

- texture (particle size) using the pipette method to obtain the relative proportions of sand, silt and clay;

- $\mathrm{pH}$ (water and $\mathrm{KCl}$ ), measured potentiometrically in a soil suspension (1:2.5) after $24 \mathrm{~h}$;

- Total Nitrogen $(\mathrm{N})$ by the Kjeldahl semi-micro method [11];

- Available Phosphorus (P) by the Bray II method [12]; 

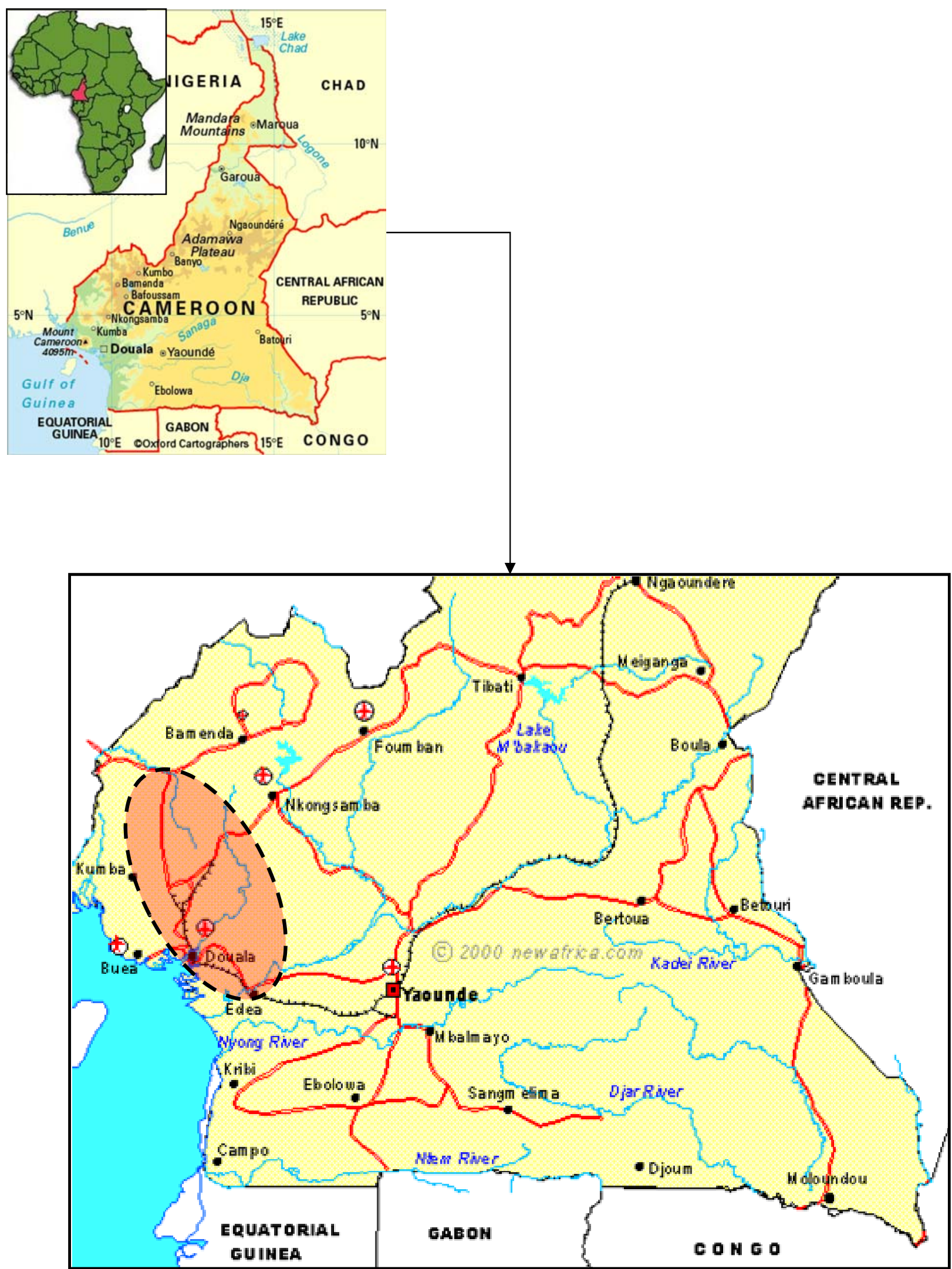

Figure 1. Map of Cameroon showing the study site. 
Table 1. Farmholdings covered during the study.

\begin{tabular}{|c|c|c|c|c|c|c|c|}
\hline Plot & Village & Main crop & Development of main crop & Altitude (m) & Slope (\%) & Clay (\%) & FSU \\
\hline 18 & Bombe & Oil palm & In production & 208 & 1 & 35 & A \\
\hline 21 & Bombe & Cocoa & Immature & 45 & 3 & 30 & A \\
\hline 22 & Malende & Cocoa & Immature & 67 & 5 & 35 & A \\
\hline 23 & Bombe & Cocoa & Immature & 89 & 3 & 40 & $\mathrm{C}$ \\
\hline 24 & Malende & Cocoa & Immature & 38 & 3 & 30 & A \\
\hline 25 & Bombe & Cocoa & In production & 45 & 0 & 40 & $\mathrm{C}$ \\
\hline 26 & Bombe & Cocoa & In production & 28 & 0 & 40 & $\mathrm{C}$ \\
\hline 27 & Bombe & Cocoa & In production & 56 & 20 & 40 & $\mathrm{D}$ \\
\hline 28 & Malende & Oil palm & Immature & 87 & 13 & 30 & $\mathrm{~B}$ \\
\hline 29 & Malende & Oil palm & Immature & 56 & 3 & 30 & A \\
\hline 30 & Bombe & Oil palm & Immature & 34 & 4 & 30 & A \\
\hline 31 & Bombe & Oil palm & In production & 25 & 5 & 30 & A \\
\hline 32 & Bombe & Oil palm & In production & 56 & 3 & 25 & A \\
\hline 33 & Bombe & Oil palm & In production & 85 & 3 & 30 & A \\
\hline 34 & Bombe & Rubber & Immature & 82 & 3 & 30 & A \\
\hline 35 & Bombe & Rubber & Immature & 67 & 1 & 30 & A \\
\hline 36 & Bombe & Rubber & Immature & 65 & 2 & 30 & A \\
\hline 37 & Bombe & Rubber & In production & 69 & 1 & 30 & A \\
\hline 38 & Bombe & Rubber & In production & 70 & 25 & 40 & $\mathrm{D}$ \\
\hline
\end{tabular}

- Exchangeable bases calcium (Ca), magnesium (Mg), potassium (K) and sodium (Na) by the neutral ammonium acetate leaching method [13,14];

- Aluminium and hydrogen ions $\left(\mathrm{Al}^{+} \mathrm{H}\right)$ by leaching with $1 \mathrm{M} \mathrm{KCl}[13,14]$;

- The soil bulk density was determined from soil cores using the Cylinder method $[15,16]$. Soil samples were dried at $105^{\circ} \mathrm{C}$ to constant weight, and the bulk density was recorded as the ratio of the mass of the dried soil (in $\mathrm{g}$ ) to the internal volume of the core cutter (in $\mathrm{cm}^{3}$ ).

\subsection{Data Collection and Analysis Using NUTMON ${ }^{\circledR}$}

The NUTMON ${ }^{\circledR}$ tool, applied at both the farm and activity levels, included a structured questionnaire, a database, and two static models - NUTCAL for calculation of nutrient flows and the ECCAL for calculation of economic parameters [17]. A user interface facilitated data entry, data manipulation and data extraction to produce input for both models.

An initial inventory of household composition, farm and field layout, agricultural activities and nutrient stocks was completed for each farm. This inventory was followed by a monthly monitoring of on-farm agricultural activities that affect nutrient flows. The activities of the farm family, their cash income and the allocation of labour were also recorded.

Based on the algorithm of the NUTMON ${ }^{\circledR}$ software, the obtained data were modelled to obtain nutrient balances (inputs less outputs) for all the farms. Nutrient output included harvested crop products and residues, nutriants leached out below the root zone, gaseous losses from the top soil, erosion and human excreta lost because it ends up in deep pit latrines far below the root zone. Nutrient inputs into the system were mineral fertilisers, organic inputs (manure, imported crop residues and feeds), air-borne deposition, biological $\mathrm{N}$-fixation by plants, sedimentation and nutrients extracted from the sub-soil by deep-rooting crops and trees.

\section{Results and Discussion}

\subsection{Characterisation of Farm Sections}

Initial assessment as shown in Figure 2 (not derived using the NUTMON ${ }^{\circledR}$ ), showed that plantain and cassava were the most intercropped annual crops while cocoa, and to a slightly lesser extent, oil palm were the most intercropped perennial crops in the study area. In effect, the two respective crops in each category accounted for more that $50 \%$ of observed intercropped frequencies.

Interviews confirmed that the farmers were aware of the progressive decline in land productivity over the years, a phenomenon attributed to continuous cropping on the same fields, soil erosion and most especially the diminishing supplies of manure. However, they were not aware of the fate of macro nutrients in these processes and/ 
or how this affected their soil productivity.

\subsection{Analysis of Nutrient Flows in Farm Units}

The overall N-P-K nutrient flows showed that these flows varied with the nutrients under consideration and with the distribution factors considered (Figure 3).

$\mathrm{N}, \mathrm{P}$ and $\mathrm{K}$ in-flows seemed to be evenly distributed between imported organic fertiliser (IN1a), wet and dry atmospheric deposition (IN3), N-fixation (IN4) and to a lesser extent the minerals in harvested produce. This, however, was not the case for out-flows as the proportions varied considerably with the nutrients considered. First, the greatest nutrient loss was that of nitrogen, and this was mainly attributed to leaching ( 70\%), volatilization ( $20 \%$ ), and to exported crops and crop residues. Very little of $\mathrm{P}$ and $\mathrm{K}$ were lost from the farms. Instead, these
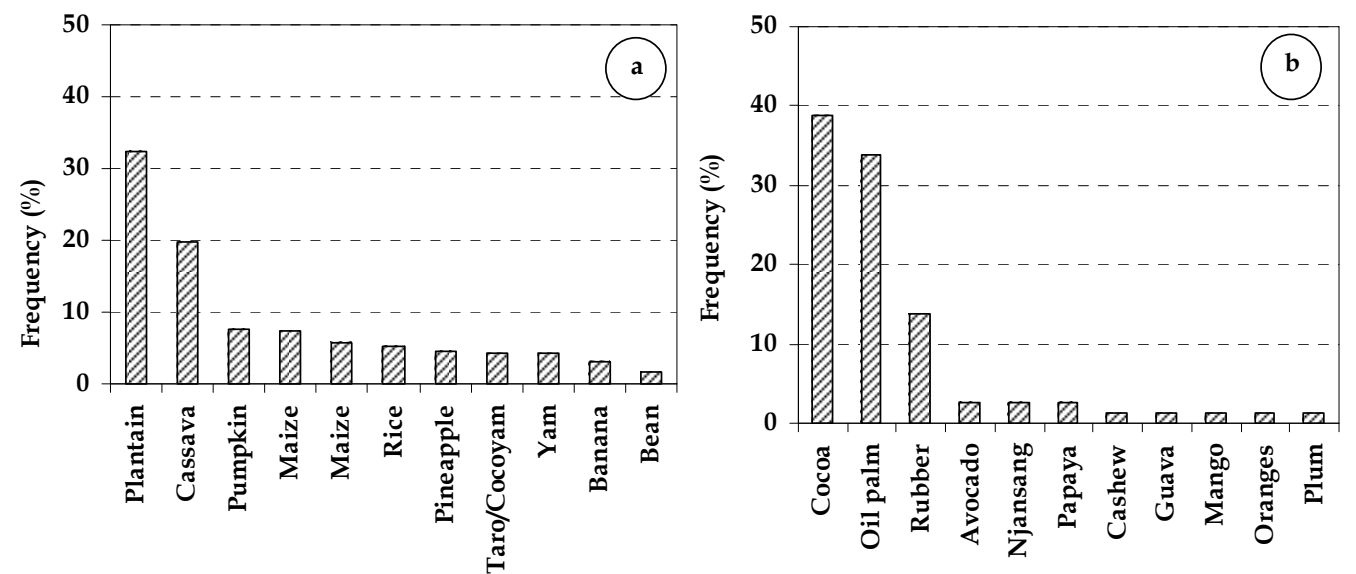

Figure 2. Frequency of occurrence of the main (a) annual crops and (b) perennial crops associated in the perennial crop based smallholdings.

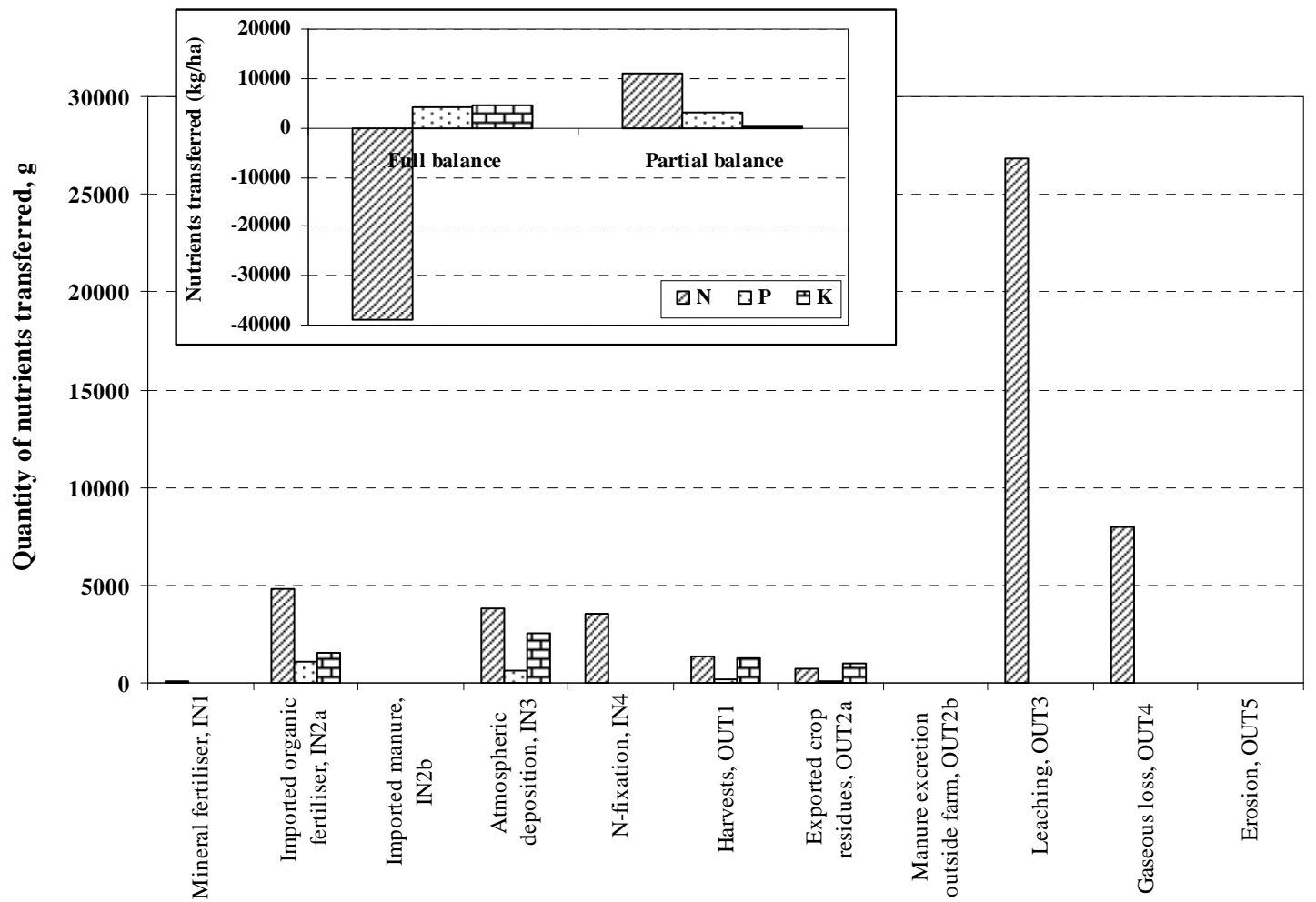

Figure 3. Overall N-P-K nutrient flows for the farms studied, as well as the specific full and partial balance of N-P-K nutrient transfers (insert). 
nutrients were mostly obtained from imported organic fertilisers and atmospheric deposition. These figures were confirmed by the rather different overall balances, negative for nitrogen and positive for phosphorus and potassium (Figure 3(a)). On ignoring all losses due to leaching (partial nutrient balance), the overall figures became positive for the three elements, especially for N (Figure 3, insert). This demonstrated that farmers may have inadvertently compensated for depletion provoked by harvesting of farm produce by returning global biomass at the plot level.

\subsection{Nutrient Flows between Farm Units}

Full and partial balances of the nutrients showed large differences between farm units (Figure 4). Whereas all farm units had negative full balances for nitrogen (Figure 4(a)), only about one-quarter of them had a negative partial balance for that nutrient (Figure 4(b)). This situation was slightly different for $\mathrm{K}$ transferred, but much different for P. Indeed, almost all the farm units had positive full and partial balances for $\mathrm{P}$ while a small proportion of them continued to have negative values for $\mathrm{K}$ for both the full and partial balances. These results indicate clearly that leaching might be the most important factor contributing to loss of soil nutrients, especially nitrogen.

When all the farms were considered as a farm section unit (FSU), the contribution of various modelled factors to the overall nutrient status (Figure 5) as well as to the full and partial nutrient balances (Figure 5, insert) changed considerably. From these, it could be shown that atmospheric deposition was responsible for most of the $\mathrm{N}$ nutrient transferred into the FSU, followed by $\mathrm{N}$ fixation and imported organic fertiliser. Once more, leaching and gaseous loss accounted for most of the $\mathrm{N}$ loss while harvested produce and the exported crop residues accounted for $\mathrm{P}$ and $\mathrm{K}$ loss.

Net nutrient losses in soil $\mathrm{N}, \mathrm{P}$ and $\mathrm{K}$ were much more pronounced in cocoa and oil palm based fields than the Hevea ones. This will certainly be related to the multiplicity of products harvested from the oil palm and cocoa fields compared to the rubber fields which give essentially C, captured though photosynthesis.
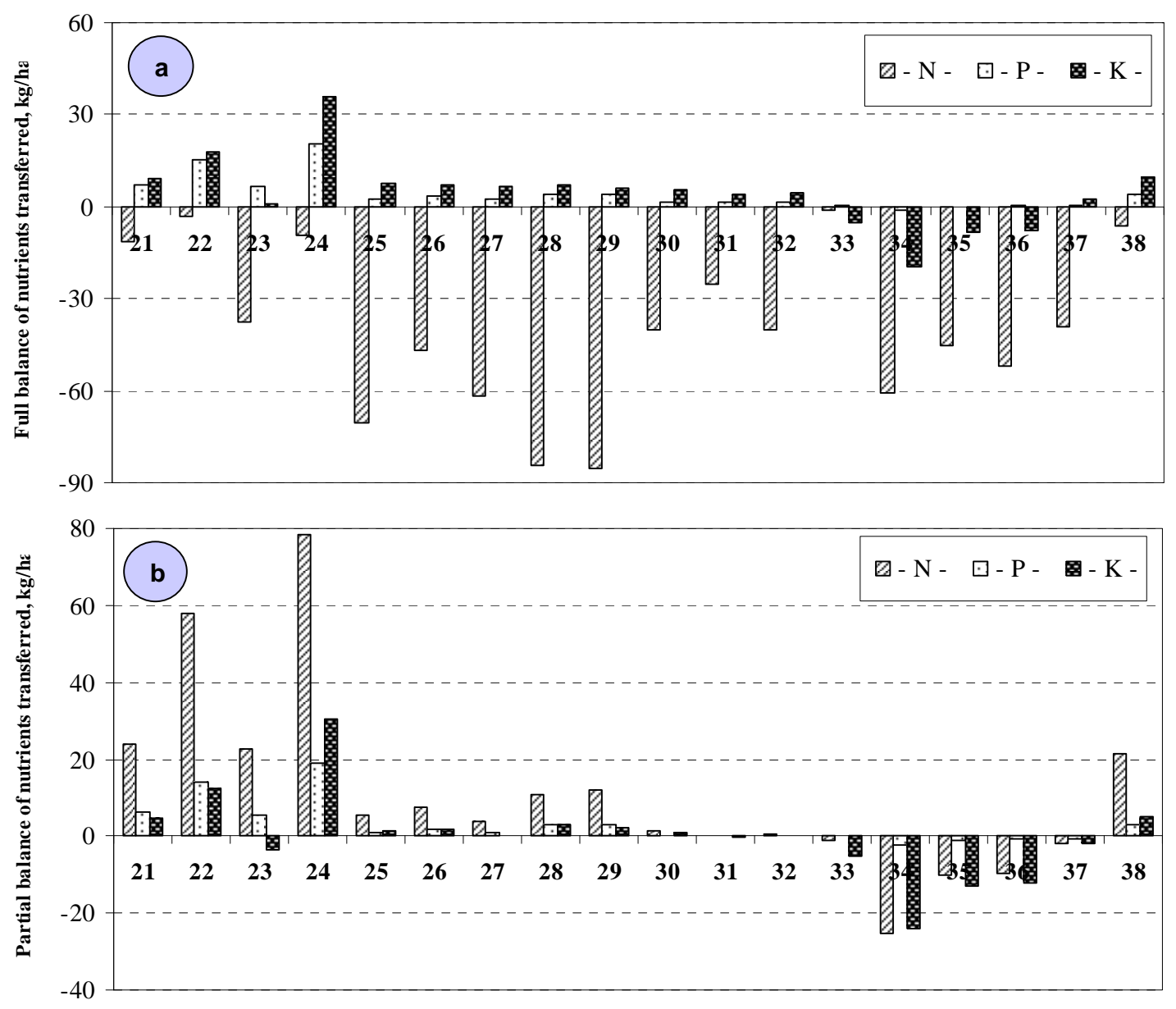

Figure 4. Specific full and partial balance of overall N-P-K nutrient transfers for the individual farm units. 


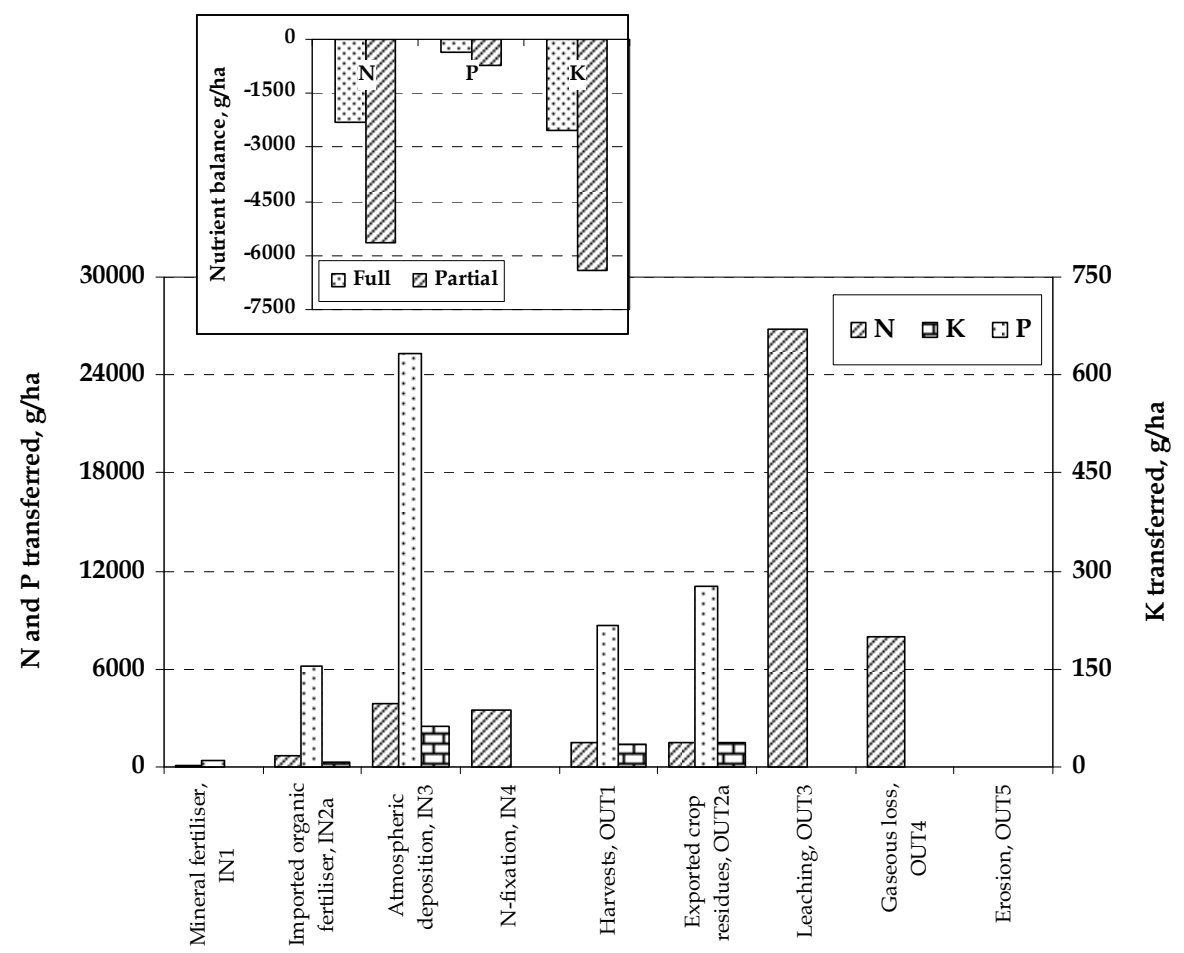

Figure 5. Contribution of various factors to the N-P-K nutrient balance in the farm section unit (FSU) and their contributions to the total nutrient balance (insert).

Table 2. Flows per unit outside the farm for the entire farm section unit.

(a) Rubber farm

\begin{tabular}{ccccccc}
\hline Movement & Material & Fresh, kg/ha & Dry, kg/ha & $\mathrm{N}, \mathrm{kg} / \mathrm{ha}$ & $\mathrm{P}, \mathrm{kg} / \mathrm{ha}$ & $\mathrm{K}, \mathrm{kg} / \mathrm{ha}$ \\
\hline OUT & Rubber coagula & 737 & 295 & 0.8 & 0.3 & 0.8 \\
OUT & Pineapple fruit & 4 & 1 & 0.0 & 0.0 & 0.0 \\
IN & Formic acid & 4 & 4 & 0.0 & 0.0 & 0.0 \\
IN & Ethrel & 1 & 1 & 0.0 & 0.0 & 0.0 \\
\hline
\end{tabular}

(b) Oil palm farm

\begin{tabular}{cccccccc}
\hline in/out & material & Fresh, kg/ha & Dry, kg/ha & N, kg/ha & P, kg/ha & K, kg/ha \\
\cline { 6 - 7 } OUT & Cassava - tuber & 467 & 177 & 0.7 & 0.1 & 0.7 \\
OUT & Oil palm nuts & 459 & 459 & 10.7 & 15.6 & 20.9 \\
OUT & Palm oil & 3560 & 3560 & 12.1 & 160.2 & 12.7 \\
OUT & Pumpkin - seeds & 80 & 72 & 0.6 & 0.1 & 0.2 \\
IN & Calash & 1 & 1 & 0.0 & 0.0 & 0.0 \\
IN & 20/10/10 & 5 & 5 & 1.0 & 0.2 & 0.4 \\
IN & Maize - grain & 4 & 3 & 0.1 & 0.0 & 0.0 \\
IN & Okra - grain & 0 & 0 & 0.0 & 0.0 & 0.0 \\
IN & Plantain - sucker & 70 & 70 & 0.3 & 0.3 & 0.1 \\
IN & Yam - tuber & 23 & 6 & 0.0 & 0.0 & 0.0 \\
IN & Pumpkin - grain & 11 & 10 & 0.1 & 0.0 & 0.0 \\
IN & Insecticides & 1 & 1 & 0.0 & 0.0 & 0.0 \\
IN & Plantain - bunch & 23 & 4 & 0.0 & 0.0 & 0.0 \\
IN & Maize - cob & 30 & 26 & 0.4 & 0.1 & 0.1 \\
IN & Taro/cocoyam tuber & 15 & 15 & 0.1 & 0.1 & 0.2 \\
\hline
\end{tabular}




\begin{tabular}{|c|c|c|c|c|c|c|}
\hline in/out & Material & Fresh, kg/ha & Dry, kg/ha & $\mathrm{N}, \mathrm{kg} / \mathrm{ha}$ & $\mathrm{P}, \mathrm{kg} / \mathrm{ha}$ & $\mathrm{K}$, kg/ha \\
\hline OUT & Cocoa - grain & 122 & 122 & 4.0 & 5.6 & 0.4 \\
\hline OUT & Pineapple - fruit & 3 & 1 & 0.0 & 0.0 & 0.0 \\
\hline OUT & Plantain - bunch & 3681 & 626 & 0.8 & 0.2 & 2.8 \\
\hline OUT & Rice - grain & 60 & 54 & 0.6 & 0.2 & 0.2 \\
\hline OUT & Cassava - processed & 70 & 27 & 0.1 & 0.0 & 0.1 \\
\hline OUT & Groundnuts & 220 & 209 & 7.8 & 1.3 & 1.7 \\
\hline IN & Potato - tuber & 10 & 2 & 0.0 & 0.0 & 0.0 \\
\hline IN & Cocoa - seedlings & 450 & 450 & 9.0 & 2.1 & 1.5 \\
\hline IN & Rice - grain & 68 & 61 & 0.7 & 0.2 & 0.2 \\
\hline IN & Cassava - tuber & 78 & 29 & 0.1 & 0.0 & 0.1 \\
\hline IN & Maize - cob & 338 & 294 & 4.9 & 1.2 & 1.4 \\
\hline IN & Plantain - sucker & 395 & 395 & 1.4 & 1.8 & 0.7 \\
\hline IN & Cocoa - seeds & 560 & 560 & 18.5 & 25.8 & 2.0 \\
\hline IN & Taro/cocoyam tuber & 50 & 50 & 0.2 & 0.3 & 0.6 \\
\hline
\end{tabular}

Economic analyses, which formed a related aspect of this study but presented elsewhere [18], showed that cash crops, as compared to staple crops, could be more profitable and often associated with less negative nutrient balances than food crop because more inputs were invested in them (Table 2). At farm level, a higher nutrient loss was calculated for the more heavily intercropped fields, notably oil palm and cocoa. Indeed, these fields suffered the greatest nutrient depletion due to the multiple forms in which their products were harvested. As shown in Table 2, the Hevea fields mostly lost their nutrients following tapping and draining of their latex whereas the oil palm lost its nutrients through its harvested bunches (seeds, kernels and leaves).

As our results would indicate, nutrient balance models are valuable when using data obtained from a site or set of sites to extrapolate to larger areas [4]. However, there are limitations inherent to such aggregations, notably with respect to the representativeness of sample site(s) and the applicability of data collected at one scale (geographic or temporal) in representing processes, which may occur at broader scales [19]. NUTMON is a multi-scale approach that assesses stocks and flows of some macro-nutrients ( $\mathrm{N}, \mathrm{P}$ and $\mathrm{K}$ only) in a well defined geographical unit. It is often considered as pragmatic to carry out nutrient audits after calculating nutrient balances and evaluating trends in nutrient mining/enrichment [20]. The NUTMON model has therefore been widely adopted though the several major simplifications (coefficients for crop residue removal are the same for all crops) and its inability to measure effects of interactions between the nutrients seem to make the results less reliable [21,22]. Furthermore, the model ignores data on carbon sequestration, a factor that would much improve its usefulness and applicability.

\section{Conclusions}

Overall N-P-K flows varied with the nutrients and the distribution factors considered. The in-flow of these nutriants was evenly distributed between dry atmospheric deposition, $\mathrm{N}$-fixation and the harvested produce. Nitrogen was the nutrient lost in greatest amounts, due essentially to leaching, gaseous loss and harvesting of crops and their residues. Less important amounts of $\mathrm{P}$ and $\mathrm{K}$ were lost from the farms as substantial amounts were obtained from imported organic fertilisers and atmospheric deposition. Large differences were observed between farm units with respect to their full and partial balances of the nutrients. Despite the sustained productivity within perennial crop-based cropping systems, all farm units had negative balances for $\mathrm{N}$ and almost none for $\mathrm{P}$ and $\mathrm{K}$. Net nutrient losses in soil $\mathrm{N}, \mathrm{P}$ and $\mathrm{K}$ were much more pronounced in cocoa and oil palm based fields than the Hevea ones, probably because of the multiplicity of products harvested from former fields. The more heavily intercropped fields were subjected to greater nutrient depletion. These results could nonetheless be treated with some caution and the Nutmon software revised to eliminate its several major simplifications, its inability to measure effects of interactions between the nutrients, and its non-utilisation of carbon sequestration data, all of which seem to make the results less reliable.

\section{Acknowledgements}

This work was undertaken in the framework of the ATP CARESYS Project and funded by the Centre International de Coopération en Recherche Agronomique pour le Développement (CIRAD). The Logistic and other support of the Regional Directorate of CIRAD for Central Africa are highly appreciated. 


\section{REFERENCES}

[1] J. Kanmegne, "Slash and Burn Agriculture in the Humid Forest Zone of Southern Cameroon: Soil Quality Dynamics, Improved Fallow Management and Farmers' Perceptions,” PhD Thesis, Wageningen University and Research Centre, 2004.

[2] H. V. D. Bosch, A. de Jager and J. Vlaming, "Monitoring Nutrient Flows and Economic Performance in African Farming Systems (NUTMON) II. Tool Development," Agriculture, Ecosystems and Environment, Vol. 71, No. 1, December 1998, pp. 49-62.

[3] A. de Jager, S. M. Nandwa and P. F. Okoth, "Monitoring Nutrient Flows and Economic Performance in African Farming Systems (NUTMON) I. Concepts and Methodologies," Agriculture, Ecosystems and Environment, Vol. 71, No. 1, December 1998, pp. 39-50.

[4] E. M. A. Smaling and L. O. Fresco, “A Decision Support Model for Monitoring Nutrient Balances under Agricultural Land Use (NUTMON)," Geoderma, Vol. 60, No. 1-4, December 1993, pp. 235-256.

[5] U. Surendran, V. Murugappan, A. Bhaskaran and R. Jagadeeswaran, "Nutrient Budgeting Using NUTMON-ToolBox in an Irrigated Farm of Semi-Arid Tropical Region in India: A Micro-and Meso-Level Modelling Study,” World Journal of Agricultural Sciences, Vol. 1, No. 1, January 2005, pp. 89-97.

[6] E. E. Ehabe, M. T. Besong and S. W. Almy, "Late and Infrequent Weeding by Peasant Farmers in the Humid Forest of Cameroon,” Tropical Science, Vol. 41, No. 3, September 2001, pp. 137-141.

[7] F. L. Sinclair, “A General Classification of Agro-Forestry Practice,” Agroforestry Systems, Vol. 46, No. 2, September 1999, pp. 161-180.

[8] S. J. Epale, "Plantations and Development in Western Cameroon. 1885-1975. A Study in Agrarian Capitalism,” Vantage Press Inc., New York, 1985.

[9] C. Plaza "Situation de l'hévéaculture Villageoise dans une Filière en Évolution: Cas de la Région d'Ekona, Province du Sud-Ouest Cameroun,” M.Sc. Thesis, Université Montpellier I, France, 2003.

[10] M. T. Besong, S. W. Almy and B. Bakia, "Land Productivity of Small Farm Holders in South West Province of Cameroon," International Journal of Tropical Agriculture, Vol. 11, No. 1, March 1993, pp. 81-87.

[11] J. Jones and J. Benton, “A Kjeldahl Method of Nitrogen Determination,” Micro-Macro Publishing Inc., Athens, Georgia, USA, 1991.

[12] R. H. Bray and L. T. Kurt, "Determination of Total Org- anic Available Forms of Phosphorus in Soils," Soil Science, Vol. 59, No. 1, January 1945, pp. 39-45.

[13] C. A. Black, "Methods of Soil Analysis," American Society of Agronomy, No. 9, Part 2, Madison, Wiscosin. 1965.

[14] M. L. Jackson, "Soil Chemical Analysis,” Prentice Hall, New York, 1962.

[15] A. L. Tisdall, "Comparison of Methods of Determining Apparent Density of Soils," Australian Journal of Agricultural Research, Vol. 2, No. 4, December 1951, pp. 349- 354.

[16] B. R. Brasher, D. P. Franzmeier, V. Valassis and S. E. Davidson, "Use of Saran Resin to Coat Natural Soil Clods for Bulk Density and Moisture Retention Measurements," Soil Science, Vol. 101, No. 2, February 1966, pp. 108222.

[17] J. Vlaming, A. de Jager, R. van den Bosch, G. Meijerink, C. van Beek , S. van Wijk and H. van Keulen, NUTMON Toolbox-Data Background, Data Entry, and Data Processing Modules, v3.5-1. "Atambua". Jointly published by Envista Consultancy, Agricultural Economics Research Institute (The Netherlands), Alterra Consultancy and Plant Research International (The Netherlands), 2006. http://www monqi.org/

[18] G. S. Rodrigues, I. de Barros, E. E. Ehabe, P. Sama-Lang and F. Enjalric, "Integrated Indicators for Performance Assessment of Traditional Agroforestry Systems in South West Cameroon,” Agroforestry Systems, Vol. 77, No. 1, September 2009, pp. 9-22.

[19] P. Drechsel, M. Giordano and L. Gyiele, "Valuing Nutrients in Soil and Water: Concepts and Techniques with Examples from IWMI Studies in the Developing World," Research Report 82, Colombo, International Water Management Institute, Sri Lanka, 2004.

[20] U. Surendran and V. Murugappan, "Pragmatic Approaches to Manage Soil Fertility in Sustainable Agriculture," Journal of Agronomy, Vol. 9, No. 2, January 2010, pp. 57-69.

[21] N. R. Rabindra and R. V. Misra, "Soil Nitrogen Balance Assessment and its Application for Sustainable Agriculture and Environment,” Science in China Series C - Life Sciences, Vol. 48, No. 6, January 2005, pp. 843-855.

[22] U. Surendran and V. Murugappan, "Nutrient Budgeting in Tropical Agro Ecosystem-Modeling District Scale Soil Nutrient Balance in Western Zone of Tamil Nadu Using Nutmon-Toolbox,” International Journal of Soil Science, Vol. 2, No. 3, September 2007, pp. 159-170. 